\title{
Sağlık İle İlgili Bilgi İçeren Web Sitelerine Yönelik Etik Düzenlemeler: Ilaç Firmaları Örneği*
}

\author{
Ethical regulations for health websites: Example of pharmaceutical companies \\ Başar Kayıran', Bilge Sözen Şahneii, Selen Yeğenoğluiii
}

iUzm. Ecz., Kayıran Eczanesi, Andırın-Kahramanmaraş, https://orcid.org/0000-0003-2014-0441

iiDr. Öğr. Üy., Hacettepe Üniversitesi Eczacılık Fakültesi, Eczacılık İşletmeciliği Anabilim Dalı, https://orcid.org/0000-0003-0746-8303

iiiProf. Dr., Hacettepe Üniversitesi Eczacılık Fakültesi, Eczacılık İsletmeciliği Anabilim Dalı, https://orcid.org/0000-0002-5217-8797

Öz

Günümüzde insanın daha bilinçli olma ihtiyacı, sağılı alanında bilgi aramak için internetin kullanımının oldukça yaygınlaşmasına neden olmuştur. Bunu doğrular biçimde, ülkemizde farklı nedenlerle internet kullanan kişilerin \%65,9'unun sağlık konusunda çeşitli bilgiler aradığı bilinmektedir. Sağlık sorunlarının nedenleri ve tedavileri, bu alanda sunulan danışmanlıklar, sağlık ile ilgili çeşitli ürünler gibi pek çok farklı alan internet kullanıcılarının ulaşabileceği şekilde web sitelerinde yer almaktadır. Söz konusu bilgilerin ve ürünlerin doğruluğu ve güvenilirliği ile birlikte, kullanıcılar tarafından anlaşılırlığı pek çok probleme neden olabileceği düşünülen tartışmalı konulardır. Özellikle kaynağı konusunda netlik bulunmayan bilgiler, kişilerin sağlık davranışlarında ve dolayısıyla sağlık durumlarında olumsuz sonuçlara neden olabilmektedir. Bu nedenle, toplum sağlığına olumsuz etki edebilecek bilgi kaynaklarının önüne geçilebilmesi ve internet ortamında sağlık alanında faaliyet gösteren bilgi kaynaklarının belirli standartlara sahip olabilmesi için, çeşitli düzenlemelerin varlığı zorunlu hale gelmektedir. Bu bağlamda, ulusal ve uluslararası birçok mevzuatın yanı sıra, çeşitli kuruluşlar tarafından da etik ilkeler oluşturulmuştur. Ancak, söz konusu bu etik ilkeler, web siteleri hazırlanırken dikkate alındığı takdirde, daha anlamlı hale gelecektir. Bu nedenle, söz konusu etik ilkeler konusunda web firmaların hem de kullanıcıların farkındalıklarının arttıııması, özellikle doğru bilgiye ulaşma açısından büyük önem taşımaktadır.

Anahtar Kelimeler: Sağlık bilgisi, Etik kurallar, İnternet, İlaç Endüstrisi

\section{ABSTRACT}

The need to become more conscious has led to the widespread use of the Internet to seek information in the field of health. To confirm this, it is known that $65.9 \%$ of people who use the internet for different reasons in our country search for various information about health. Several issues such as the causes and treatments of health problems, consultations in this field, various products related to health are available on the web sites for internet users. The accuracy and reliability of such information and products, as well as the intelligibility of users are controversial issues that are thought to cause many problems. In particular, information that is not clear about the source may cause negative results in the health behaviors and health conditions of people. For this reason, the existence of various regulations becomes mandatory in order to prevent the sources of information that may have a negative impact on public health and to ensure certain standards for the health-related information sources on the internet. In addition to many national and international legislation, ethical principles have been established by various organizations. However, these ethical principles will become more meaningful if they are taken into account when preparing these websites and when users visit them. Therefore, raising the awareness of web companies and users about these ethical principles is of great importance, especially in terms of accessing the right information.

Key words: Health information, Ethical codes, Internet, Drug Industry

\footnotetext{
*Lokman Hekim Dergisi, 2020; 10 (1): 58-63

DOI: $10.31020 /$ mutftd.642334

e-ISSN: 1309-8004

Geliş Tarihi - Received:04 Kasım 2019; Kabul Tarihi - Accepted: 23 Aralık 2019

iletişim - Correspondence Author: Bilge Sözen Şahne <bilgesozen@yahoo.com>
} 


\section{Sağlık İletişimi ve İnternet}

Yaşantının vazgeçilmez bir unsuru olan iletişim, "bilginin semboller aracılığıyla bir yerden başka bir yere gönderilmesi" ${ }^{1}$ olarak tanımlansa da her alanın içinde, özelleşerek karşımıza teknik bir kavram olarak çıkmaktadır. Sağlık alanında, "Sağı̆ğın geliştirilmesi maksadıyla, bireyler arasında sağlıkla ilgili oluşan etkileşim ve işlemlerle, iletişim kavram ve kuramlarının uygulanması" 2,3 olarak açıklanan sağlık iletişimi; daha ayrıntılı olarak "önemli sağlık sorunları hakkında, kamunun, bireylerin ve kurumların bilgilendirilmesi, etkilenmesi ve harekete geçirilmesi sanat ve tekniği" şeklinde tanımlanmaktadır. ${ }^{2,4}$

Modernleşmenin beraberinde getirdiği sonuçlardan olan, daha bilinçli olma ihtiyacı, sağı̆ı alanında da kendini göstermiş ve dünyanın her yerinden, 7 gün 24 saat ulaşılabilen web siteleri, önemli bilgi kaynakları olarak ön plana çıkmıştır. ${ }^{5,6}$ Bu bağlamda, ABD'de yapılan bir ankete katılımcıların \%63'ünden fazlasının, Avrupa'da yapılan bir çalışmada kullanıcıların $\% 71^{\prime}$ inin, ülkemizde ise $\% 65,9^{\prime}$ unun sağlıkla ilgili konularda bilgi almak amacıyla interneti kullandığı belirlenmiştir. ${ }^{7-10}$

Sağlık sorunlarının nedenleri ve tedavileri, bu alanda sunulan danışmanlıklar, sağlık ile ilgili çeşitli ürünler gibi pek çok farklı alan internet kullanıcıların ulaşabileceği şekilde web sitelerinde yer almaktadır. ${ }^{11-14}$ Söz konusu bilgilerin ve ürünlerin doğruluğu ve güvenilirliği ile birlikte, kullanıcılar tarafından anlaşılırlığı pek çok probleme neden olabileceği düşünülen tartışmalı konulardır. Özellikle kaynağı konusunda netlik bulunmayan bilgiler, kişilerin sağlık davranışlarında ve dolayısıyla sağlık durumlarında olumsuz sonuçlara neden olabilmektedir. ${ }^{13,15,16}$ Buna rağmen, internet kullanıcılarının özelliklerine göre sağlık açısından olumlu yönde etkileyen faktörlerin de olduğu belirlenmiştir. Bu faktörler arasında; kişilerin eğitim düzeyleri, yaşları, uzun süreli sağıık sorunlarının yanı sıra sağlık açısından kendilerini iyi hissetmeleri yer almaktadır. ${ }^{9}$

İnternette sağlıkla ilgili web sitelerini inceleyen kişiler, başvuracakları sağlık kuruluşu ya da sağlık personeli hakkında bilgi almanın dışında, tedavi çeşitlerini ve olanaklarını araştırmak, sağlıkla ilgili ürünler hakkında bilgi almak, benzer soruları ve sorunları olan kişilerle irtibat kurmak ile kendi deneyimlerini paylaşmak için de interneti kullanmaktadır. Bununla birlikte, çok sayıda deneyime düşük maliyetle, herhangi bir sınırlamayla karşılaşmadan, hızla ulaşılabilmesi de kullanıcıların interneti tercih etme sebepleri arasında yer almaktadır. ${ }^{17}$

Internet aracılığıyla sağlık iletişiminin sürdürülmesinde, sürecin doğru bir şekilde yönetilmesinde kurumsal kaynakların ayrı bir yeri bulunmaktadır ve bu durum, kurumsal kaynaklar açısından da önemli fırsatları beraberinde getirmektedir..$^{5,18}$

\section{Sağlık Sektöründe Kurumsal Web Siteleri}

Etkili bir iletişim kanalı olarak, kurum içi ve kurum dışı paydaşlara yönelik pek çok bilginin yer aldığı kurumsal web siteleri, şirketlerin itibarı açısından da önemli bir etmendir. ${ }^{18-21}$ Bununla birlikte, kurumsal bir web sitesinin kabul edilebilir olarak değerlendirilmesi için yapılması gerekenler, sekiz ana başlıkta toplanmaktadır. ${ }^{22}$ Bu başlıklardan ilki olan "doğruluk" kriteri kapsamında; bilgilerin kaynağının belirtilmesi, yazarın deneyimi ve verilerin şeffaflığı ile ilgili sorulardır. "Yetkinlik" başlığında ise yazarın tanınırlığı ile ilgili sorulara cevap aranmaktadır. Üçüncü kriter olan "kapsam"da, sitedeki bilgilerin uygunluğu değerlendirilmektedir. "Güncellik" kriterinde, gerek sayfada yer alan bilgilerin, gerekse yapılan yönlendirmelerin güncel olup olmadığına yönelik kontrollerin yapılması gerektiğine değinilmektedir. Sayfadaki bilgilerin dağılımı ve anlaşılırlığı, "yoğunluk" kriteri kapsamında ele alınmaktadır. Web sitelerinin incelenmesinde önemli bir yeri olan, sayfayı hazırlayan kişilerin ulaşılabilirliği ile ilgili sorular ise, "etkileşim" kriteri altında yer almaktadır. "Objektiflik" kriterinde de, sitenin tarafsızlı̆ına ve amacına yönelik sorular sorulmaktadır. En son kriter olan "çabukluk" ise, günümüzün vazgeçilmez gerekliliklerinden olan hızla ilgili unsurları içermektedir. ${ }^{22}$

Sağlık pazarının vazgeçilmez bir bileşeni olan ilaç sektörü, topluma sunduğu ürünlerin niteliği açısından yenilikleri ortaya çıkaran ve uygulayan bir özellik taşımaktadır. Bu bağlamda, söz konusu sektörde faaliyet gösteren firmaların, toplum tarafından kabul edilebilirliğinin sürdürülebilmesi için sosyal fonksiyonlarını en yüksek standartta sürdürmeleri gerekmektedir. ${ }^{23,24} \mathrm{Bu}$ bağlamda, ilaç firmalarının web sitelerinin yasal ve etik kurallara uymaları büyük önem taşımaktadır. 


\section{İlaç Firmalarının Web Sitelerine Yönelik Etik Kurallar}

Internette yer alan bilgilerin sınırsızlı̆ı̆, özellikle kurumsal olarak sağılık sektöründe faaliyet gösteren şirketlerin dikkate alması gereken çeşitli ilkelerin belirlenmesini elzem kılmıştır. Bu bağlamda, uluslararası ve ulusal düzeydeki çeşitli düzenlemelere Tablo 1'de yer verilmektedir.

Tablo 1. Uluslararası ve ulusal düzeydeki çeşitli düzenlemeler

\begin{tabular}{|c|c|c|c|}
\hline Kurumun Adı & $\begin{array}{c}\text { Düzenlemenin Yer Aldığı } \\
\text { Metnin Adı }\end{array}$ & Linki & Temel ilkeler \\
\hline $\begin{array}{l}\text { Dünya Sağlık Örgütü } \\
\text { (WHO) }\end{array}$ & $\begin{array}{l}\text { Safety and security on the } \\
\text { internet: challenges and } \\
\text { advances in Member States: } \\
\text { based on the findings of the } \\
\text { second global survey on } \\
\text { eHealth }^{25}\end{array}$ & $\begin{array}{l}\text { https://apps.who.int/iris/h } \\
\text { andle/10665/44782 }\end{array}$ & Doğruluk, Güvenilirlik \\
\hline $\begin{array}{l}\text { Uluslararası İlaç } \\
\text { Üreticileri ve Dernekleri } \\
\text { Federasyonu (IFPMA) }\end{array}$ & Code Of Practice 26 & $\begin{array}{l}\text { https://www.ifpma.org/wp } \\
\text { - } \\
\text { content/uploads/2018/09/I } \\
\text { FPMA_Code_of_Practice_2 } \\
\text { 019.pdf }\end{array}$ & Doğruluk, Şeffaflık, Gizlilik \\
\hline $\begin{array}{l}\text { Avrupa İlaç Endüstrisi ve } \\
\text { Dernekleri Federasyonu } \\
\text { (EFPIA) }\end{array}$ & Code Of Practice ${ }^{27}$ & $\begin{array}{l}\text { https://efpia.eu/media/413 } \\
\text { 022/efpia-code-2019.pdf }\end{array}$ & Doğruluk, Şeffaflık \\
\hline $\begin{array}{l}\text { İnternette Sağlık Vakfı } \\
\text { (HON) }\end{array}$ & $\begin{array}{l}\text { The HON Code of Conduct } \\
29\end{array}$ & $\begin{array}{l}\text { https://www.hon.ch/HONc } \\
\text { ode/Patients/Conduct.html }\end{array}$ & $\begin{array}{l}\text { Yazarların Yetkisi, } \\
\text { Tamamlayıcılık, Gizlilik, Atıfta } \\
\text { Bulunma, Doğrulanabilirlik, } \\
\text { Kaynağın Şeffaflığı, Sponsorun } \\
\text { Şeffaflığı, İçerik ve Reklam } \\
\text { Politikasında Dürüstlük }\end{array}$ \\
\hline $\begin{array}{l}\text { Sağlık İnternet Etiği } \\
\text { (Hi-Ethics) }\end{array}$ & $\begin{array}{l}\text { Ethical Principles For Offering } \\
\text { Internet Health Services to } \\
\text { Consumers }\end{array}$ & $\begin{array}{l}\text { https://www.hiethics.org/P } \\
\text { rinciples.html }\end{array}$ & $\begin{array}{l}\text { Gizlilik, } \\
\text { Şeffaflık, Doğruluk, }\end{array}$ \\
\hline T.C. Sağlık Bakanlığı & Beşeri Tıbbi Ürünlerin Tanıtım & https://www.resmigazete.g & \\
\hline Türkiye Illaç ve Tıbbi Cihaz & Faaliyetleri Hakkında & ov.tr/eskiler/2015/07/2015 & \\
\hline Kurumu (TіTCK) & Yönetmelik 31 & 0703-2.htm & \\
\hline $\begin{array}{l}\text { Araştırmacı İlaç Firmaları } \\
\text { Derneği (AiFD) }\end{array}$ & İyi Tanıtım İlkeleri32 & $\begin{array}{l}\text { https://www.aifd.org.tr/wp } \\
\text { - } \\
\text { content/uploads/2019/10/ } \\
\text { AIFD-Iyi-Tanitim- } \\
\text { IlkeleriTR2019.pdf }\end{array}$ & Şeffaflık, Tutarlılık \\
\hline $\begin{array}{l}\text { İlaç Endüstrisi İşverenler } \\
\text { Sendikası (IEIS) }\end{array}$ & $\begin{array}{l}\text { İEis İlaç Tanıtım İlkeleri ve } \\
\text { Sağlık Mensuplarıyla İlişkiler } \\
\text { Hakkında Yönetmelik }{ }^{33}\end{array}$ & $\begin{array}{l}\text { http://www.ieis.org.tr/ieis/ } \\
\text { assets/media/files/rapor/IT } \\
\text { I_SM2013.pdf }\end{array}$ & Şeffaflık, Doğruluk \\
\hline
\end{tabular}

Dünya çapında, sağıık alanındaki en büyük ve en üst düzey organizasyon olarak kabul edilen Dünya Sağlık Örgütü (DSÖ-WHO), internette yer alan sağlık bilgilerinden bahsettiği çalışmasında, doğruluk ve güvenilirliğin önemine yer verirken, Health On the Net Foundation Code of Conduct (HONCode)'a atıfta bulunmaktadır. ${ }^{25}$ Bu kapsamda, HON (Health On the Net)'un, özellikle internet kullanıcıların güvenilirlik açısından, doğru sağıı bilgisine ulaşabilmeleri için sağladığı standardizasyon süreci vurgulanmaktadır. Merkezi İsviçre'de bulunan bu kuruluşun standartlarının, 100'den fazla ülkede 10 milyonun üzerinde web sitesinde kullanıldığı belirtilmektedir. Ayrıca, arama motoru aracılı̆ıyla kullanıcıların sağlıkla ilgili bilgiler sunan güvenilir web sitelerine ulaşabileceğinden bahsedilmektedir. ${ }^{25}$

IFPMA (Uluslararası İlaç Üreticileri ve Dernekleri Federasyonu-International Federation of Pharmaceutical Manufacturers and Associations)'nın ilkelerinde; firmaların, toplumla iletişim açısından, faaliyet gösterdikleri ülkenin kurallarına uyması gerektiği vurgulanmaktadır. Bu ilkeler kapsamında, dürüstlük, şeffafık, gizlilik, doğruluk gibi unsurlara yer verilmektedir. ${ }^{26}$ Söz konusu kuruluşun 2019 yılında güncellenen "Code of Practice" başlıklı etik kurallarında, sağlık çalışanlarıyla kurulacak ilişkiden sürekli tıp eğitiminin desteklenmesine kadar pek çok alanda yürütülecek tutundurma faaliyetlerine yönelik düzenlemeler 
bulunmaktadır. Bu kılavuzun elektronik kaynaklarla ilgili bölümünde, sunulan bilgilerin doğruluğuyla birlikte içeriğin, hedeflenen kullanıcıya uygun şekilde düzenlemesi gerektiği belirtilmektedir. Bunun yanı sıra, IFPMA'nın kendi internet sitesinde de sunulan içeriğin şeffaflı̆ının önemi ile ilgili bilgiler bulunmaktadır. ${ }^{26}$

EFPIA (European Federation of Pharmaceutical Industries and Associations-Avrupa ilaç Endüstrisi ve Dernekleri Federasyonu)'nın üyelerinin yaptıkları tanıtım faaliyetlerinde dikkat etmeleri gereken hususlara yer verdiği kılavuzda, doğruluk ve şeffaflık ön plana çıkmaktadır. ${ }^{27} 2019$ yılında güncellenen ve 6 bölümden oluşan "Code of Practice" belgesi, IFPMA'nınkine benzemektedir. Bu belgede yer verilen etik kuralların, yapılan tüm faaliyetlerin odağında, hastaların bulunduğu bilinciyle oluşturulduğu dikkati çekmektedir. Üye kuruluşların web siteleri ile ilgili öneriler kapsamında faaliyet gösterilen ülkedeki düzenlemeler özelinde, sunulan bilgilerin açık, anlaşılır ve güncel olması gerektiği vurgulanmaktadır. ${ }^{27}$

Internet Sağıı Hizmeti Koalisyonu (Internet Healthcare Coalition), kar elde etme amacı olmayan ve faaliyetlerini bağımsız olarak yürüten bir kuruluştur. Bu koalisyonun hazırladığı E-Sağlık Etik Kodları (The eHealth Code of Ethics) - HON prensipleri (Health on the Net Code); "Yazarların Yetkisi, Tamamlayıcılık, Gizlilik, Atıfta Bulunma, Doğrulanabilirlik, Kaynağın Şeffaflığı, Sponsorun Şeffaflığı, İçerik ve Reklam Politikasında Dürüstlük" olmak üzere, toplam 8 başlıktan oluşmaktadır. Bu prensipleri karşılayan, sağlıkla ilgili web siteleri, kalitelerini gösterebilmek için HON'un hazırladığı logoya web sitelerinde yer vermektedir. ${ }^{28,29}$ Aralarında Türkçe'nin de bulunduğu 40'a yakın dile çevrilen ilkeler; dünyada pek çok sağlık kuruluşu ile birlikte, çeşitli sağlık sorunları ile ilgili sivil toplum kuruluşları ve sağlıkla ilgili bilgi veren web sitelerinde uygulanmaktadır. HON prensiplerinde ilk kural olarak, web sitelerinde verilen bilgilerin sağık konusundaki uzmanlar tarafından verilmesi gerektiği belirtilmektedir. Bununla birlikte son güncelleme tarihi, site ziyaretçilerinin gizliliği, siteyi hazırlayanların ulaşılabilirliği verilen bilgilerin sadece destekleyici bilgiler olduğunun belirtilmesi gibi kurallar da bulunmaktadır. ${ }^{28,29} \mathrm{HON}$, bu değerlendirme ve sertifikasyon sürecinin, tamamen, çevrim içi içerikte insan sağlığının korunmasına odaklandığını vurgulamaktadır. HON'un kendi web sitesi incelendiğinde, logoyu kullanma hakkı verilen web siteleri ile ilgili güncel bilgilere de ulaşılabilmektedir. ${ }^{29}$

Health Internet Ethics (Sağlık İnternet Etiği-Hi-Ethics) 14 prensipten oluşan bir etik kural zinciri oluşturmuştur ve kurallar içerisine gizlilik ön plana çıkmaktadır. ${ }^{30}$ internet kullanıcılarına yönelik sağlıkla ilgili web sitelerinde gizlilik, reklam ve içerik kalitesi gibi konulara dikkat çekmek amacıyla, 1999'da kurulan HiEthics'in kurallarının, Amerika Birleşik Devletleri'nde URAC (the Utilization Review Accreditation Commission) tarafından da doğrulandığı belirtilmektedir. Hi-Ethics'in 14 prensibi içerisinde, kullanıcıların gizliliği ile birlikte, HONcode da olduğu gibi, finansal kaynakların şeffaflığı, verilen bilgilerin doğrulanabilirliği ve kullanıcı geri bildirim mekanizması gibi çeşitli düzenlemeler bulunmaktadır. ${ }^{30}$

Ülkemizde ise bu alandaki düzenlemelerin T.C. Sağlık Bakanlığı tarafından yapıldığı görülmektedir. Bu bağlamda, "Beşeri Tıbbi Ürünlerin Tanıtım Faaliyetleri Hakkında Yönetmelik", Türkiye İlaç ve Tıbbi Cihaz Kurumu (TіTCK) tarafından yayınlanmış ve sağlık ile ilgili ürünlerin tanıtımına yönelik faaliyetlerle ilgili düzenlemeler yapılmıştır. Söz konusu yönetmelikte, ürünlerin topluma tanıtımının yapılamayacağı, TiTCK'nın onayladığı kullanma talimatlarının (KT) ve kısa ürün bilgilerinin (KÜB) sadece tanımlanmış yerlerde yayınlanabileceği gibi konular vurgulanmaktadır. ${ }^{31}$ Ayrıca, yönetmelik hükümlerine aykırı durumlarda uygulanacak yaptırımlara da yer verilmektedir.

Türkiye'deki Araştırmacı İlaç Firmaları Derneği (AiFD), aynı zamanda IFPMA ve EFPIA üyesidir. Derneğin hazırladığı "Iyi Tanıtım ve İyi Iletişim Illkeleri”nde yer alan "Ziyaretçi bilgilerinin korunması", "Bilimsel tutarlılık" gibi başlıklar IFPMA ile EFPIA'nın kuralları ile örtüşmektedir. Bu unsurların yanı sıra; halka ve sağlık meslek mensuplarına yönelik bölümlerin ayrılması, "Bu sitedeki bilgiler, bir hekim veya eczacıya danışmanın yerine geçemez. Daha fazla/ayrıntılı bilgi için bir hekime ve/veya bir eczacıya başvurunuz" uyarısının gerekli olan her sayfada bulunması gibi konuların yer aldığı 19 ayrı kural yer almaktadır. ${ }^{32}$ illki 2004 yılında yürürlüğe giren ilkelerin en güncel hali 1 Ocak 2019'dan itibaren geçerli olacak şekilde hazırlanmıştır. Web sitelerinde verilen sağlık ile ilgili bilgilerin kaynak belirtilerek verilmesi gerektiği, bu bilgilerin tanıtım olarak yorumlanmasını sağlayacak şekilde düzenlenmemesinin önemi, sıkça vurgulanmaktadır. Ayrıca, ürün tanıtımı olarak değerlendirilebilecek web sayfalarının da sadece hekim ve eczacıların erişebileceği şekilde 
düzenlenmesinin gerekliliği vurgulanmaktadır. Söz konusu ilkelerin, kurumların web siteleri ile birlikte sosyal medya hesaplarını da kapsamasının son derece önemli olduğu düşünülmektedir. ${ }^{32}$

Avrupa Eşdeğer Illaç Birliği (EGA), Avrupa Reçetesiz ilaç Üreticileri Birliği (AESGP) ve Türkiye İşveren Sendikaları Konfederasyonu (TISK) üyesi olan İlaç Endüstrisi İşverenler Sendikası (IEIS)'nın da konu ile ilgili çeşitli düzenlemeleri bulunmaktadır. "Tanıtım illkeleri ve Sağlık Mensuplarıyla Illişkiler Hakkında Yönetmelik" her ne kadar yasal mevzuat açısından kılavuz niteliği taşısa da 2012 yılında genel kurulun yaptığı değişiklikle yönetmelik ismini almıştır. Bu düzenlemelerin, "ilaç Firmalarına Ait İnternet Siteleri Uygulama illkeleri" bölümüyle, ilgili sitenin ana sayfası ve sağlık çalışanları için hazırlanan sayfalarına yönelik şekilde ayrı ayrı yapılmıştır. ${ }^{33}$ Ana sayfaya ilişkin düzenlemelerde, AiFD'de olduğu gibi sağlık çalışanları ve halka yönelik bölümlerin ayrılmasının ve "Bu sitedeki bilgiler, hekim ve eczacıya danışmanın yerine geçemez" uyarısının bulunmasının gerekliliği ile birlikte, diğer düzenlemelerde de yer alan konulara değinilmektedir. Hekim ve eczacılara yönelik sayfalarla ilgili düzenlemelerde ise sitenin uzman kişiler tarafından hazırlanmasının gerekliliği ve ürün tanıtımında, Bakanlığın onay verdiği KÜB/KT bilgilerinin dışında bilgilerin kullanılamayacağı gibi esaslar bulunmaktadır. ${ }^{33} \mathrm{Bu}$ durumun, topluma beşeri tıbbi ürünlerin tanıtımının yapılamayacağı ilkesi doğrultusunda düzenlendiği belirtilmektedir. Ayrıca, başka sitelere yapılan yönlendirmeler neticesinde ulaşılan bilgilerin, yönlendiren kuruluşla ilgisinin olmayacağı da belirtilmektedir. Gerek HONcode gerekse diğer ilkelerde de yer verilen, güncelleştirme tarihi, kaynak gösterme gerekliliği ve web sitesini hazırlayanların ulaşılabilirliği ile ilgili ifadeler, bu metinde de yer almaktadır. ${ }^{33} 1990$ 'dan beri varlığını sürdüren bu ilkelerin, yapılan güncellemelerle mevcut uygulamalara uyum sağlaması, hasta güvenliği ve toplum sağlığı açısından da önem taşımaktadır.

\section{Sonuç}

İnternette sağlıkla ilgili bilgi veren web sitelerine yönelik çeşitli düzenlemeler yapanların, çoğunlukla gönüllü katılım esasıyla oluşturulan sivil toplum örgütleri oldukları dikkat çekmektedir. Bu nedenle, söz konusu kılavuzlara uyum açısından yaptırım ve denetimler konusunda yetersizlikler bulunmaktadır. Ayrıca, gerek web sitelerini hazırlayanların gerekse site ziyaretçilerinin, son derece önemli olan bu ilkeler konusunda farkındalıklarının yeterli olmadığı düşünülmektedir. Yukarıda da yer verilen düzenlemelerin birçoğunda; şeffaflık, doğruluk gibi ortak ilkelerin bulunduğu görülmektedir. Bu alanda faaliyet gösteren kişilerin ve kullanıcıların en azından bu ortak ilkeler hususunda farkındalığııı arttırılmasının, özellikle sağlık alanında doğru bilgiye ulaşma konusunda elzem olduğuna inanılmaktadır.

\section{BiLGi}

Bu çalışma, Uzm. Ecz. Başar Kayıran'ın “Türkiye'de Faaliyet Gösteren Illaç Firmalarının Web Siteleri Üzerine Bir Araştırma" başlıklı yüksek lisans tezinden türetilmiştir.

\section{KAYNAKLAR}

1. Burgoon JK, Buller DB, Woodall WG. Nonverbal communication: The unspoken dialogue. New York: Harper \& Row; 1989.

2. Schiavo R. Health communication from theory to practice. San Francisco: A Wiley Imprint; 2007.

3. Tabak RS. Sağılık iletişimi. 2. Baskı. İstanbul: Literatür Yayınları; 2003.

4. Parrott R. Emphasizing communication in health communication. J Commun 2004; 54(4): 751-787.

5. Hülür V. Sağlık iletişimi, medya ve etik: Bir sağlık haberinin analizi. CBÜ Sosyal Bilimler Dergisi 2016;14(1):10.18026/cbusos.87810

6. Özsarıl H, Hoşgör H, Gündüz Hoşgör D. Hastane web site performanslarının halkla ilişkiler ve tanıtım açısından incelenmesi: Türkiye, Hindistan ve İrlanda örnekleri. ACU Sağlık Bil Derg 2016;4:209-217

7. Türkiye İstatistik Kurumu (TÜiK). Hanehalkı bilişim teknolojileri kullanım araştırması. [internet]. 2016. [Erişim Tarihi: Ağustos 2018]. Erişim adresi: http://www.tuik.gov.tr/PreHaberBultenleri.do?id=21779.

8. Türkiye İstatistik Kurumu (TÜiK). İnternet kullanım istatistikleri. [ỉnternet]. [Erişim Tarihi: Temmuz 2019]. Erişim adresi: www.tuik.gov.tr/prehaberbulteni.do?id=24862.

9. Andreassen HK, et al European citizens' use of e-health services: A study of sevencountries. BMC Public Health 2007;7:53.

10. Pew Research Center. Health Online. [internet]. [Erişim Tarihi: Mayıs 2018]. Erişim adresi: http://pewinternet.org/Reports/2013/Health-online.aspx. 
11. Townsend A, et al. E-Health, participatory medicine, and ethical care: A focus group study of patients and health care providers. Use of health-related internet information. J Med Internet Res 2015;17(6):155.

12. World Health Organization. Medical products and the internet: A guide to finding reliable information. [internet]. [Erişim Tarihi: Mayıs 2018]. Erişim adresi: http://apps.who.int/medicinedocs/en/d/Js2277e/

13. Yılmaz E. Türkiye'de hastaların internette tıbbi enformasyon arama davranışlarının doktor-hasta iletişimine etkileri. Galatasaray Üniversitesi İletişim Dergisi 2013;Özel Sayı 3:93-108.

14. Bogenschutz MP. Drug information libraries on the internet. J Psychoactive Drugs 2000;32(3):249-258.

15. Akpınar Söylemez B, Gönen Şentürk S, Küçükgüçlü Ö, Demans sendromu ile ilgili Türkçe web sayfalarının içeriğinin incelenmesi. Dokuz Eylül Üniversitesi Hemşirelik Fakültesi Elektronik Dergisi 2012; 5(4): 150-156.

16. Bass S. How will internet use affect the patient? A review of computer network and closed internet based system studies and the implications in understanding how the use of the internet affects patient populations. J Health Psychol 2003;8(1):25-38.

17. Esin MN, et al. Erişkin bireylerin ilaç kullanma ile ilgili davranışları, iÜFN Hem Derg 2007;15 (60): 139-145.

18. Gökdağı G. Kurumsal itibar yönetimi aracı olarak firmaların web sitelerinin değerlendirilmesi. [Yüksek Lisans Tezi]. İstanbul: İstanbul Teknik Üniversitesi; 2010.

19. García-Borbolla FA, Larrán JM, López R. Empirical evidence concerning SMEs' corporate websites: Explaining factors, strategies and reporting. The International Journal of Digital Accounting Research 2005;5(10):171-202.

20. Koçer S. Kurumsal web sitelerinin kurum kimliği açısından incelenmesi: En çok tercih edilen üniversiteler üzerine bir analiz. Uluslararası Sosyal Araştırmalar Dergisi 2017;10(53):756-772.

21. Campbell D, Cornelia Beck A. Answering allegations: The use of the corporate website for restorative ethical and social disclosure. Business Ethics: A European Review 2004; 13(2-3):100-116.

22. Dragulanescu NG. Website quality evaluations: Criteria and tools. Intl Inform \& Libr Rev 2002; 34: 247-254.

23. Van den Bogaert S, et al. In the land of pharma: A qualitative analysis of the reputational discourse of the pharmaceutical industry. Public Relations Inquiry 2018;7(2):127-147.

24. Quintero G, Henry Bundy H. Most of the time you already know: Pharmaceutical information assembly by young adults on the Internet. Subst Use Misuse 2011; 46(7): 898-909.

25.WHO Global Observatory for eHealth. Safety and security on the internet: challenges and advances in Member States: based on the findings of the second global survey on eHealth. [internet] [Erişim Tarihi: Ekim 2019]. Erişim adresi: https://apps.who.int/iris/handle/10665/44782

26. IFPMA Code of Practice. [İnternet] [Erişim Tarihi: Ekim 2019]. Erişim adresi: https://www.ifpma.org/wpcontent/uploads/2018/09/IFPMA_Code_of_Practice_2019.pdf

27. EFPIA Code of Practice. [internet] [Erişim Tarihi: Ekim 2019]. Erişim adresi: https://efpia.eu/media/413022/efpia-code-2019.pdf

28. Boyer C, Selby M, Scherrer JR, Appel RD. The health on the net code of conduct for medical and health websites computers. Comput Biol Med 1998;28:603-610.

29. Health On The Net-Hon Foundation. The HON Code of Conduct. [internet] [Erişim Tarihi: Ekim 2019]. Erişim adresi: https://www.hon.ch/HONcode/Patients/Conduct.html

30. Health Internet Ethics. Ethical Principles For Offering Internet Health Services to Consumers. [internet] [Erişim Tarihi: Ekim 2019]. Erişim adresi: https://www.hiethics.org/Principles.html

31. TC Resmi Gazete. Beşeri Tıbbi Ürünlerin Tanıtım Faaliyetleri Hakkında Yönetmelik. 3 Temmuz 2015. Sayı: 29405 https://www.resmigazete.gov.tr/eskiler/2015/07/20150703-2.htm

32. AiFD İyi Tanıtım İlkeleri. [internet] [Erişim Tarihi: Ekim 2019]. Erişim adresi: ttps://www.aifd.org.tr/wpcontent/uploads/2019/10/AIFD-Iyi-Tanitim-IlkeleriTR2019.pdf

33. İEis İlaç Tanıtım Illkeleri ve Sağlık Mensuplarıyla İlişkiler Hakkında Yönetmelik. [İnternet] [Erişim Tarihi: Ekim 2019]. Erişim adresi: http://www.ieis.org.tr/ieis/assets/media/files/rapor/ITI_SM2013.pdf 